\title{
Preparation and characterization of starch-poly-e-caprolactone microparticles incorporating bioactive agents for drug delivery and tissue engineering applications
}

\author{
E.R. Balmayor ${ }^{\mathrm{a}, \mathrm{b}, *}$, K. Tuzlakoglu ${ }^{\mathrm{a}, \mathrm{b}}$, H.S. Azevedo ${ }^{\mathrm{a}, \mathrm{b}}$, R.L. Reis ${ }^{\mathrm{a}, \mathrm{b}}$ \\ a 3B's Research Group - Biomaterials, Biodegradables and Biomimetics, Department of Polymer Engineering, University of Minho, \\ Headquarters of the European Institute of Excellence on Tissue Engineering and Regenerative Medicine, AvePark, Zona Industrial da Gandra, \\ S. Cláudio do Barco, 4806-909 Caldas das Taipas, Guimarães, Portugal \\ ${ }^{\mathrm{b}}$ IBB - Institute for Biotechnology and Bioengineering, PT Government Associated Laboratory, Braga, Portugal
}

Received 11 July 2008; received in revised form 2 October 2008; accepted 13 November 2008

Available online 3 December 2008

\begin{abstract}
One limitation associated with the delivery of bioactive agents concerns the short half-life of these molecules when administered intravenously, which results in their loss from the desired site. Incorporation of bioactive agents into depot vehicles provides a means to increase their persistence at the disease site. Major issues are involved in the development of a proper carrier system able to deliver the correct drug, at the desired dose, place and time. In this work, starch-poly-e-caprolactone (SPCL) microparticles were developed for use in drug delivery and tissue engineering (TE) applications. SPCL microparticles were prepared by using an emulsion solvent extraction/evaporation technique, which was demonstrated to be a successful procedure to obtain particles with a spherical shape (particle size between 5 and $900 \mu \mathrm{m}$ ) and exhibiting different surface morphologies. Their chemical structure was confirmed by Fourier transform infrared spectroscopy. To evaluate the potential of the developed microparticles as a drug delivery system, dexamethasone (DEX) was used as model drug. DEX, a well-known component of osteogenic differentiation media, was entrapped into SPCL microparticles at different percentages up to $93 \%$. The encapsulation efficiency was found to be dependent on the polymer concentration and drug-to-polymer ratio. The initial DEX release seems to be governed mainly by diffusion, and it is expected that the remaining DEX will be released when the polymeric matrix starts to degrade. In this work it was demonstrated that SPCL microparticles containing DEX can be successfully prepared and that these microparticular systems seem to be quite promising for controlled release applications, namely as carriers of important differentiation agents in TE.
\end{abstract}

(C) 2008 Acta Materialia Inc. Published by Elsevier Ltd. All rights reserved.

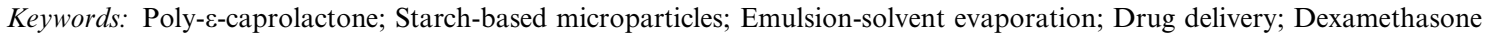

\section{Introduction}

Materials of natural origin have been studied and proposed for a wide range of biomedical applications [1-4].

\footnotetext{
* Corresponding author. Address: 3B's Research Group - Biomaterials, Biodegradables and Biomimetics, Department of Polymer Engineering, University of Minho, Headquarters of the European Institute of Excellence on Tissue Engineering and Regenerative Medicine, AvePark, Zona Industrial da Gandra, S. Cláudio do Barco, 4806-909 Caldas das Taipas, Guimarães, Portugal. Tel.: +351 253 510900; fax: +351 253510909 .

E-mail address: erosado@dep.uminho.pt (E.R. Balmayor).
}

Materials such as collagen, alginate, hyaluronic acid, silk fibroin, chitosan and starch are among the most studied polymers with numerous advantages depending on the specific applications [5-13]. One of the most relevant benefits of using materials of natural origin is their biodegradability inside the human body. Biodegradable systems have the ability to function satisfactorily for a certain time and subsequently to degrade into products easily cleared from the body, with no need for surgery for their removal. This is a particularly desirable property for the design of carriers for the controlled delivery of therapeutic drugs, since it will permit the entrapped drug to be released slowly, allowing 
repeating dosages and ensuring the successful effect of the treatments [14] as the polymer carrier degrades.

Starch-based polymers have been studied and proposed in the last decade by Reis and coworkers [13,15-21] for several biomedical applications, such as drug delivery carrier systems, hydrogels and partially degradable bone cements, materials for bone replacement/fixation or fillers for bone defects, and porous structures to be used as scaffolds in tissue engineering of bone and cartilage. These materials were found to be biocompatible [16,22-23], noncytotoxic, biodegradable [24-27] and have shown a great processing versatility [13]. These blended materials have potential application as carriers for the controlled release of different bioactive agents in the form of microparticular systems. Indeed, biodegradable starch-based microparticles have been widely investigated and proposed as drug delivery systems [28-30]. For instance, starch microparticles using soluble potato starch have been developed and proposed for the release of a nonsteroidal anti-inflammatory drug [21]. Moreover, a blend of starch and polylactic acid have been used for the encapsulation of steroids, growth factors and bioactive glass in a microparticle system [31-33]. These studies showed that the starch-polylactic acid microparticles are suitable carriers for the controlled release of bioactive agents for bone tissue engineering applications. In addition, derivatives of starch, such as starch acetate or poly(acryl starch), have been described for the incorporation and release of peptides and proteins [34-36]. However, to our knowledge there has so far been no report in the literature on the development of microparticle systems based on starch-polycaprolactone blended materials. The combination of a hydrophilic natural material (starch) with a hydrophobic synthetic polymer (polycaprolactone), both biodegradable and biocompatible, in a single blended material constitutes the major advantage of these microparticles.

Numerous controlled release systems have been developed, ranging from implants $[37,38]$ to novel osmotically driven pills [38]. The use of noninvasive delivery methods, such as injectable systems in the form of nano and microparticles, will bring substantial benefits when compared with some surgical techniques. It has already been reported that injectable systems made of nano and microparticles could be applied as carriers of different drugs and bioactive agents within the field of tissue engineering (e.g. differentiation agents and growth factors $[39,40])$. Dexamethasone (DEX) has been widely used in clinical applications to treat immuno-disorders [41,42], but a more specific and common use has been the control of the inflammatory response and tissue repair during organ transplantation [43]. In the last years, the use of this corticosteroid as an osteogenic agent has increased considerably in in vitro cell culture to induce the differentiation of stem cells into an osteoblastic lineage [41,44-46].

This study aims to establish experimental conditions for the production of a biodegradable and biocompatible microparticular system with different characteristics (e.g. size, size distribution, surface morphology) that can be used as a potential carrier for the delivery of important bioactive agents. For that, we have used a polymeric blend of starch with polycaprolactone. The microparticular system was characterized in terms of particle size, size distribution, surface morphology and chemical structure. The carrier potential was evaluated by encapsulating DEX into the microparticles and its release behavior studied in vitro.

\section{Materials and methods}

\subsection{Materials}

A polymeric blend of corn starch with poly- $\varepsilon$-caprolactone (SPCL, 30-70 wt.\%) was used in this study. More details about the thermal properties of this polymeric blend can be found elsewhere [47]. Methylene chloride and polyvinyl alcohol (PVA) were obtained from Sigma, and used as received. Unless otherwise indicated, the molecular weight (MW) of the PVA used was in the range 30,000-70,000 g $\mathrm{mol}^{-1}$ DEX ( $97 \%$, cell culture tested, Sigma) was used as a bioactive molecule for the encapsulation studies. Solvents for high-performance liquid chromatography (HPLC) (acetonitrile and water) were HPLC grade (LABSCAN). Triamcinolone was used as internal standard for DEX quantification. Potassium bromide ( $\mathrm{KBr}$ ) for IR spectroscopy $(\geqslant 99.5 \%)$ was obtained from Sigma. Other chemicals were of reagent grade, all from Sigma, and used as received.

\subsection{Preparation of SPCL microparticles}

SPCL microparticles were prepared by using an emulsion solvent extraction/evaporation technique [48]. Briefly, SPCL was dissolved in $5 \mathrm{ml}$ of methylene chloride under vigorous stirring. This solution was dropped into a $200 \mathrm{ml}$ PVA solution, and emulsified for $4 \mathrm{~h}$ at different stirring rates. Different experimental conditions were evaluated, and the details of each condition are summarized in Table 1. The microparticles where then collected by filtration, washed with distilled water and vacuum dried in a desiccator. For the selected condition to be loaded with DEX, SPCL was mixed with the steroid at different percentages $(5,10$ and $15 \%(\mathrm{w} / \mathrm{w})$, relatively to polymer weight) and dissolved in methylene chloride. The same procedure was performed as described for unloaded microparticles. The reaction medium was stored at $4{ }^{\circ} \mathrm{C}$ for later quantification of unloaded DEX. All experiments were carried out in triplicate.

\subsection{Physicochemical characterization of SPCL microparticles}

\subsubsection{Morphological analysis: scanning electron microscopy} (SEM) and micro-computed tomography $(\mu-C T)$

To analyze the morphology and surface of the microparticles obtained under the different experimental conditions, the samples were mounted onto aluminium stubs with a 
Table 1

Effect of the experimental conditions employed during microparticle production on the size and morphology of the resulting microparticles.

\begin{tabular}{|c|c|c|c|c|c|c|}
\hline Condition & $\begin{array}{l}\mathrm{SPCL}^{\mathrm{a}} \\
(\%)\end{array}$ & $\begin{array}{l}\text { Emulsification medium } \mathrm{PVA}^{\mathrm{b}}(\%)[\mathrm{MW} \\
\left.\left(\mathrm{g} \mathrm{mol}^{-1}\right)\right]\end{array}$ & $\begin{array}{l}\text { Stirring rate } \\
(\mathrm{rpm})\end{array}$ & $\begin{array}{l}\text { Reaction time } \\
(\mathrm{h})\end{array}$ & $\begin{array}{l}\text { Particle size } \\
(\mu \mathrm{m})\end{array}$ & $\begin{array}{l}\text { Shape/surface }{ }^{\mathrm{c}} \\
(\mathrm{SEM})\end{array}$ \\
\hline I & 5 & 1 & 600 & 4 & $102.3 \pm 4.1$ & $\mathrm{~s} / \mathrm{s}$ \\
\hline II & 5 & 0.5 & 600 & 4 & $200.4 \pm 3.7$ & $\mathrm{~s} / \mathrm{s}$ \\
\hline III & 10 & 0.5 & 600 & 4 & $575.1 \pm 4.6$ & $\mathrm{r} / \mathrm{p}$ \\
\hline IV & 10 & $\mathbf{1}[30,000-70,000]$ & 600 & 4 & $499.6 \pm 4.8$ & $\mathrm{r} / \mathrm{p}(\mathrm{HP})$ \\
\hline V & 10 & $1[70,000-100,000]$ & 600 & 4 & $702.1 \pm 19.0$ & r/p(HPD) \\
\hline VI & 10 & 1 & 800 & 4 & $283.0 \pm 21.0$ & $\mathrm{r} / \mathrm{p}(\mathrm{HPD})$ \\
\hline VII & 10 & 1 & 400 & 4 & $913.7 \pm 9.8$ & $\mathrm{r} / \mathrm{p}(\mathrm{HPD})$ \\
\hline VIII & 10 & 2 & 600 & 4 & $376.0 \pm 3.2$ & $\mathrm{r} / \mathrm{p}$ \\
\hline IX & 10 & 5 & 600 & 4 & $324.1 \pm 15.3$ & r/p(HPD) \\
\hline $\mathrm{X}$ & 15 & 1 & 600 & 4 & $770.0 \pm 8.7$ & $\mathrm{r} / \mathrm{p}$ \\
\hline XI & 20 & 1 & 600 & 4 & $810.0 \pm 16.2$ & $\mathrm{r} / \mathrm{p}(\mathrm{HPD})$ \\
\hline XII & 10 & 1 & 20,000 & 4 & $5.73 \pm 8.19$ & $\mathrm{~s} / \mathrm{s}$ \\
\hline
\end{tabular}

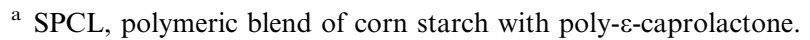

${ }^{\mathrm{b}}$ PVA, polyvinyl alcohol.

${ }^{\mathrm{c}} \mathrm{s} / \mathrm{s}$, spherical/smooth; r/p, round/porous; HPD, high polydispersity; HP, highly porous.

carbon tape and gold sputter-coated (Fisons Instruments, Sputter Coater SC502, UK). All images were collected with a Leica Cambridge S-360 model (Cambridge, UK) scanning electron microscope.

Microparticle samples with porous surfaces (experimental condition III, see Table 1 for details) were scanned by micro-computed tomography $(\mu-\mathrm{CT})$ using a $\mu$-CT 20 equipment (SCANCO Medicals, Switzerland). The energy of the scanner used was $100 \mathrm{kv} / 98 \mu \mathrm{A}$ intensity. A threshold range of values of 141-255 was used to estimate the porosity of the samples. Approximately 40 slices of the sample were obtained. Mimics (Materialise, Belgium), CT Analyser and CT Vol Realistic 3D Visualization (SkyScan, Belgium) software were used for image processing and to create and visualize the three-dimensional representation.

\subsubsection{Size distribution}

To determine the size distribution of the microparticles obtained under the different experimental conditions, the microparticles were separated through a series of standard sieves $(20,60,100,125,150,250,450,500,650,900$ and $1000 \mu \mathrm{m}$; Linker Industrie-Technik, Germany). The microparticle fraction that passed through a sieve and was retained on the sieve with a certain pore size was collected and weighed, and finally correlated with the total mass of the microparticle sample analyzed.

\subsubsection{Fourier transform infrared (FTIR) spectroscopy}

The chemical structure of the microparticles (unloaded, loaded with DEX and after release) was analyzed by FTIR (IRPrestige-21 FRIT-8400S, Shimadzu, Japan) in transmission mode. For that, microparticles $(1 \mathrm{mg})$ were mixed with $\mathrm{KBr}(40 \mathrm{mg})$ and then formed into a disc in a manual press (161-1100 hand press, Pike Technologies, Madison, WI). Transmission spectra were recorded using at least 32 scans with $4 \mathrm{~cm}^{-1}$ resolution, in the spectral range 4000 $600 \mathrm{~cm}^{-1}$.

\subsubsection{X-ray diffraction $(X R D)$}

In order to confirm the encapsulation and release of DEX into and from the SPCL microparticles, and to access the physical state of the entrapped drug, X-ray diffraction patterns of DEX and SPCL microparticles (unloaded, loaded with DEX and after the release studies) were obtained in a X-ray diffractometer (X'Pert MPD, Philips, The Netherlands). The data collection was performed with a $\mathrm{Cu}$ anode and monochromator used at a voltage of $40 \mathrm{kV}$. The samples were analyzed over the angle range (20) $2^{\circ}-60^{\circ}$.

\subsection{Determination of DEX encapsulation efficiency and release profile from SPCL microparticles}

\subsubsection{Encapsulation efficiency}

The encapsulation efficiency of DEX into the SPCL microparticles was calculated using the following equation:

$\%$ Encapsulation eff $\cdot=\left[\left(C_{i}-C_{r}\right) / C_{i}\right] \times 100$,

where $C_{i}$ is the initial concentration of DEX added, and $C_{r}$ is the concentration of unloaded DEX (remaining in the reaction medium: PVA solution where loaded microparticles were produced). DEX concentration was determined by HPLC (see Section 2.5). Determinations were made in triplicate and the average is reported.

\subsubsection{In vitro release of $D E X$ from $S P L C$ microparticles}

Pre-weighed SPCL-DEX-loaded microparticles were suspended in $40 \mathrm{ml}$ of PBS (pH 7.4, $0.01 \mathrm{M}$ ) at a concentration of $2.5 \mathrm{mg} \mathrm{ml}^{-1}$. The microparticles were maintained at $37^{\circ} \mathrm{C}$ under constant agitation $(50 \mathrm{rpm})$ for 30 days in a shaking bath. At predetermined time points, first each $30 \mathrm{~min}$, then each 1 and $2 \mathrm{~h}$, and 4, 5, 7, 10, 14, 30 days, 
$1 \mathrm{ml}$ aliquots of the supernatant were taken and replaced with the same volume of fresh PBS solution. DEX concentration was quantified by HPLC. All the release experiments were carried out in triplicate and the average is reported.

\subsection{Quantification of DEX by $H P L C$}

Before HPLC analysis, samples from the reaction medium were extracted three times with a mixture of hexane and ethyl acetate in the same proportions. The final extract was collected and the solvent allowed to evaporate under nitrogen flow. The dry extract was reconstituted in a mixture of acetonitrile/water $(50: 50 \mathrm{v} / \mathrm{v}$, mobile phase) before analysis. The aliquots from the release medium (PBS solution containing released DEX) were analyzed directly as taken.

DEX was quantified by reverse-phase (RP) HPLC. HPLC was performed on a Jasco PU-2080 Plus system using a RP-18 column (LiChrospher, $5 \mu \mathrm{m}$, Merck, Germany) with acetonitrile/water $(50: 50 \mathrm{v} / \mathrm{v})$ as mobile phase at a flow rate of $0.5 \mathrm{ml} \mathrm{min}{ }^{-1}$. Absorbance was monitored at $254 \mathrm{~nm}$ (UV detector Jasco 870-UV). The column was eluted in isocratic conditions over $20 \mathrm{~min}$. Data acquisition and peak areas were determined with a Shimadzu C-R6A Chromatopac software. The concentration of DEX was calculated by using a calibration curve $\left(y=8697.18+\left(1.65 \times 10^{7}\right) x, R^{2}=0.9995\right)$. Triamcinolone was used as internal standard.

\section{Results and discussion}

3.1. Preparation of SPCL microparticles: evaluation of the effect of different experimental conditions on particle size and morphology

In order to optimize the proposed methodology for the production of SPCL microparticles with different morphological characteristics and sizes, several experimental conditions were tested (summarized in Table 1).

Four different polymeric (SPCL) concentrations were studied to investigate the effect of this parameter on the size and morphology of the microparticles. Fig. 1 shows the morphological characteristics of the SPCL microparticles obtained with different polymeric concentrations.

The viscosity of the SPCL solution is directly related to the polymeric concentration [49]. Consequently, at higher concentrations of SPCL, there is a rather significant increase in the viscosity of the solution and, as result, the size of the drops in the emulsification medium is higher, which leads to an increase the microparticle size (experimental conditions I, IV, X, XI: see Table 1). It was found that at polymer concentrations higher than $10 \%$ the polydispersity increases due to the higher particle size obtained under these conditions. It was also observed that at higher polymeric concentrations, the microparticles exhibit a porous surface, as shown in Fig. $2 \mathrm{~b}$ and $\mathrm{c}$, when compared with the smooth morphology of the microparticles obtained at lower polymer concentrations (Fig. 2a). A representative sample (experimental condition IV, Table 1)
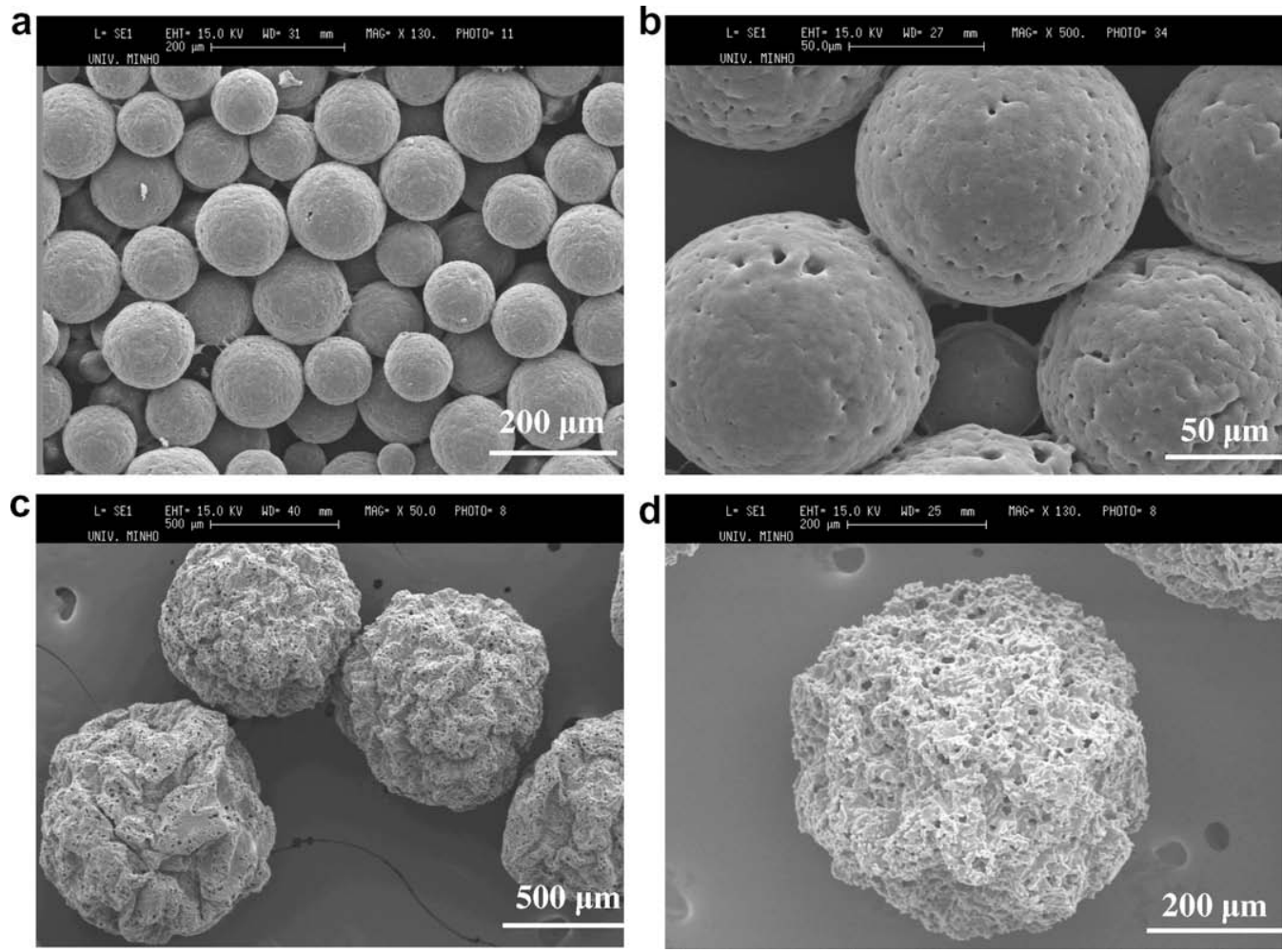

Fig. 1. SEM micrographs of SPCL microparticles obtained under different experimental conditions: (a and b) Condition I-SPCL 5\%; (c and d) condition IV-SPCL $10 \%$ (see Table 1 for details). 

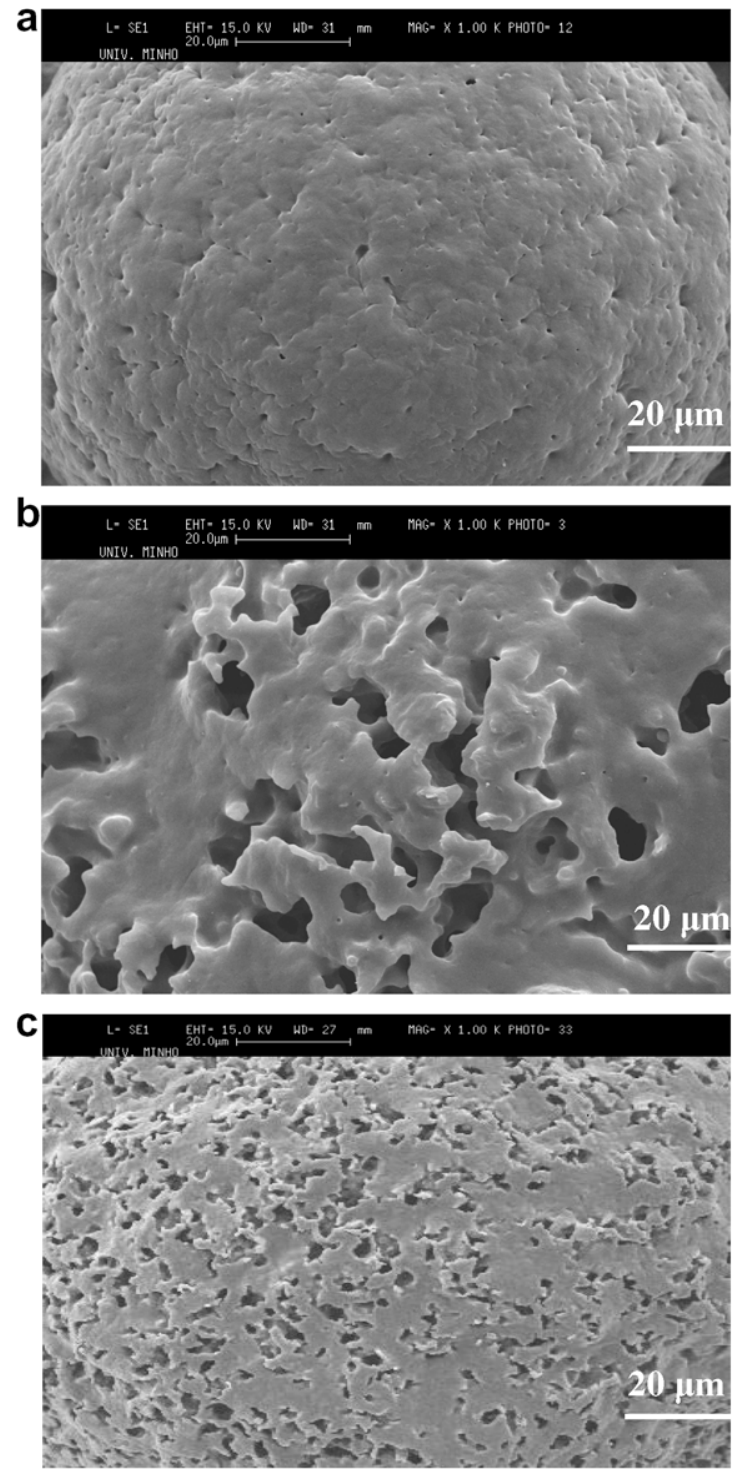

Fig. 2. SEM micrographs of the surface of SPCL microparticles showing different morphologies when using different polymer concentrations: (a) Condition I-SPCL 5\%; (b) condition IV-SPCL 10\%; (c) condition XISPCL $20 \%$ (see Table 1 for details).

from porous microparticles was analyzed by micro-CT scan (Fig. 3). As result, $44 \%$ porosity was obtained, which indicated that $10 \%$ of polymer concentration is adequate for the production of microparticles with a porous structure.

By means of selecting the polymer concentration in the range of $5-10 \%$, it is possible to obtain microparticles with a desired size range $(100-600 \mu \mathrm{m})$, a narrow size distribution as illustrated in Fig. 4, and different surface morphologies.

The effect of the reaction medium composition was also studied, by the varying the concentration of PVA in the emulsification medium from 0.5 to $5 \%$. The use of PVA as an emulsion stabilizer results in a quite successful preparation of SPCL microparticles. By analyzing the results presented in Table 1, it can be observed that the size of the microparticles slightly decreases as the PVA concentration increases (experimental conditions III, IV, VIII, IX: see Table 1), but this effect was not as significant as the one observed for the polymer concentration. The spherical shape of the microparticles is lost as the concentration of PVA becomes higher than $2 \%$, and the surface of the microparticles becomes more porous. Analyzing the effect of PVA molecular weight (MW), it was found a noticeable increase in the size of the microparticles (experimental conditions IV, V: see Table 1), when the PVA MW range increased from $30,000-70,000$ to $70,000-100,000 \mathrm{~g} \mathrm{~mol}^{-1}$. Therefore, a concentration of 0.5 and $1 \%$ PVA with a MW range $30,000-70,000 \mathrm{~g} \mathrm{~mol}^{-1}$ was selected as optimum, avoiding loss of spherical shapes, deformation of particles and uncontrolled particle size.

One of the most important factors affecting the microparticle size is the stirring speed during their preparation [50]. It has been already shown in the literature [51] that by varying the stirring speed from hundreds to thousands of rpm, micro to nanoparticles can be produced. In our experiments, we observed that by increasing the stirring rate, the size of the microparticles drastically decreased (experimental conditions VII (400 rpm), IV (600 rpm), VI $(800 \mathrm{rpm})$ and XII $(20,000 \mathrm{rpm})$ in Table 1$)$. In fact, an increase in the stirring speeds provides higher energy to disperse two immiscible phases (oil in water phase) and form the emulsion, producing smaller drops of oil phase in the water (because it is breaking the oil phase into smaller drops) and as a result smaller particles are obtained. Fig. 5 shows the morphological characteristics and the size of the SPCL microparticles obtained with higher stirring speeds.

\subsection{Physicochemical characterization of unloaded SPCL microparticles}

Iodine-potassium solution (Lugol) is a well-known and useful solution for chemically identifying the presence of starch molecules [31]. The amylose present in the starch molecule has a helical secondary structure [52], where substances such as iodine can lodge, forming a complex as an inclusion compound. This starch-iodine forms a coloured complex (dark blue), and this property can be used to identify the presence and distribution of starch in complex polymeric blends. Staining with Lugol solution was performed for all experimental conditions. These experiments revealed the presence of starch in the microparticles, since a dark blue staining was observed in all conditions. A more intense staining was observed in the microparticles with a porous surface. This may due to the diffusion of iodine to the interior of the microparticles in this case, while in the microparticles with smooth surface the iodine is mainly reacting with the starch molecules present at the surface of the microparticles.

The infrared spectrum of SPCL microparticles exhibits the same characteristic peaks of the raw material before processing (the infrared spectrum of SPCL raw material 

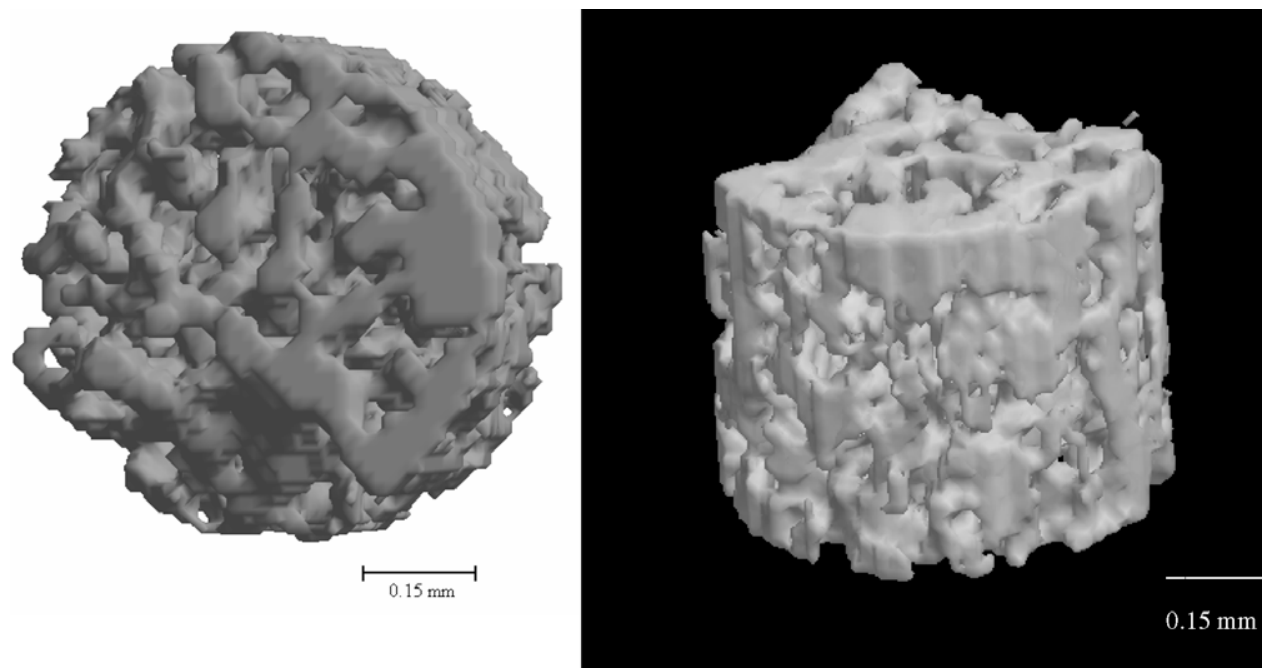

Fig. 3. Micro-CT three-dimensional reconstruction of the SPCL microparticle illustrating the porosity of the obtained particulate structure (experimental condition IV: see Table 1).

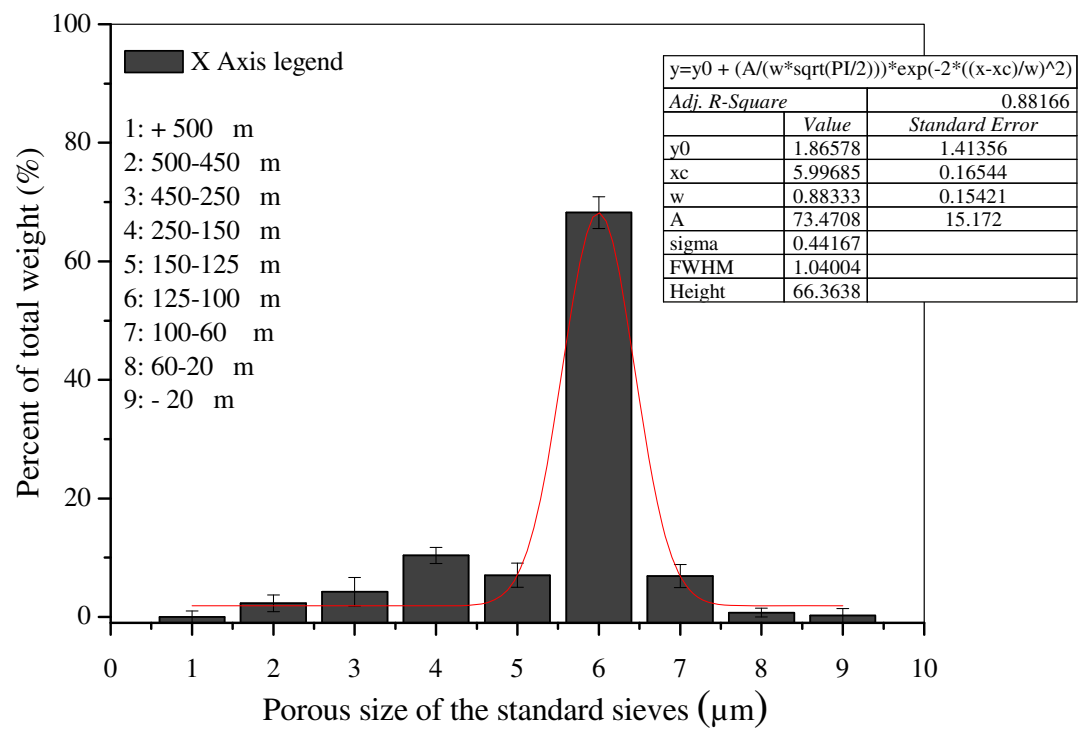

Fig. 4. Size distribution of the SPCL microparticles (experimental condition I: see Table 1).
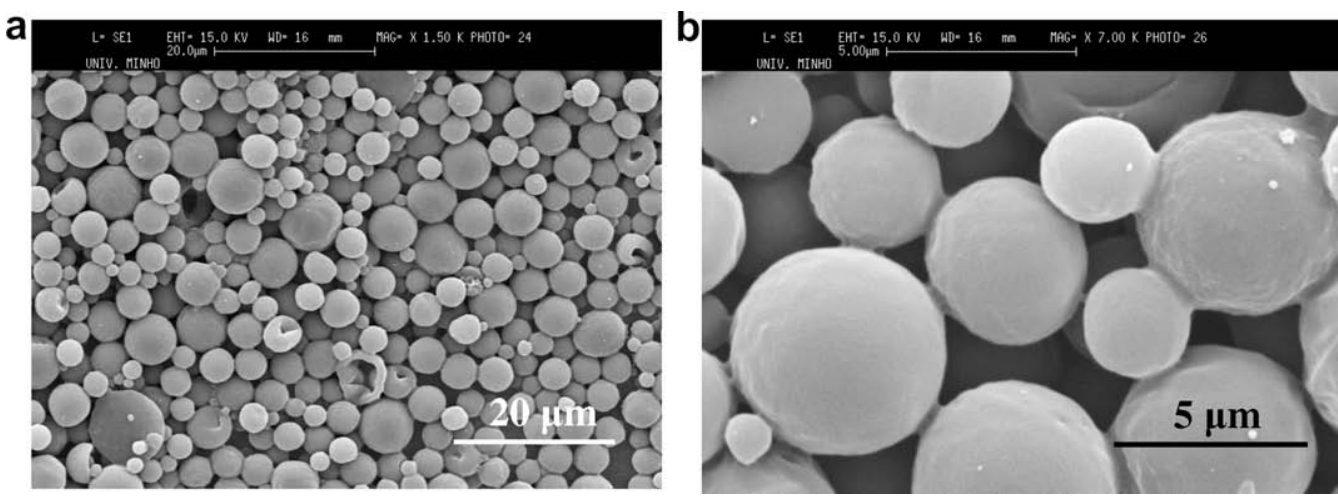

Fig. 5. SEM micrographs of SPCL microparticles obtained at higher stirring speed, at (a) lower and (b) higher magnification. Condition XII-20,000 rpm, resulting in a stronger decrease in the size of the resulting microparticles. 
Table 2

Characteristic IR bands of the microparticle components (starch and polycaprolactone) $[12,27]$.

\begin{tabular}{lll}
\hline $\mathrm{cm}^{-1}$ & Vibration & Abbreviation \\
\hline $2944 / 2864$ & $\begin{array}{l}\text { (from } P C L) \text { Asymmetric/ } \\
\text { symmetric } \mathrm{CH}_{2} \text { stretching }\end{array}$ & $\mathrm{v}_{\mathrm{as}}\left(\mathrm{CH}_{2}\right), \mathrm{v}_{\mathrm{s}}\left(\mathrm{CH}_{2}\right)$ \\
& $\mathrm{C}=\mathrm{O}$ stretching & $\mathrm{v}(\mathrm{C}=\mathrm{O})$ \\
1724 & Asymmetric COC stretching & $\mathrm{v}_{\mathrm{as}}(\mathrm{COC})$ \\
1195 & OC-C stretching/symmetric & $v(\mathrm{OC}-\mathrm{O}), \mathrm{v}_{\mathrm{s}}(\mathrm{COC})$ \\
3362 & COC stretching & \\
$1021 / 1048$ & (from starch) OH stretching & $v(\mathrm{OH})$ \\
\hline
\end{tabular}

has been described in previous publications [25,53-55]). The bands from PCL and starch were easily identified. The strongest bands and their assignments are summarized in Table 2. This demonstrates that both components of the blend remained present in the chemical structure of the obtained microparticles.

\subsection{Determination of DEX encapsulation efficiency and in vitro release profile}

For the loading of DEX and in vitro release experiments, conditions I-IV (Table 1) were selected for the preparation of SPCL microparticles. Using these conditions, DEX-loaded microparticles were successfully produced. The obtained microparticles exhibited a morphology very

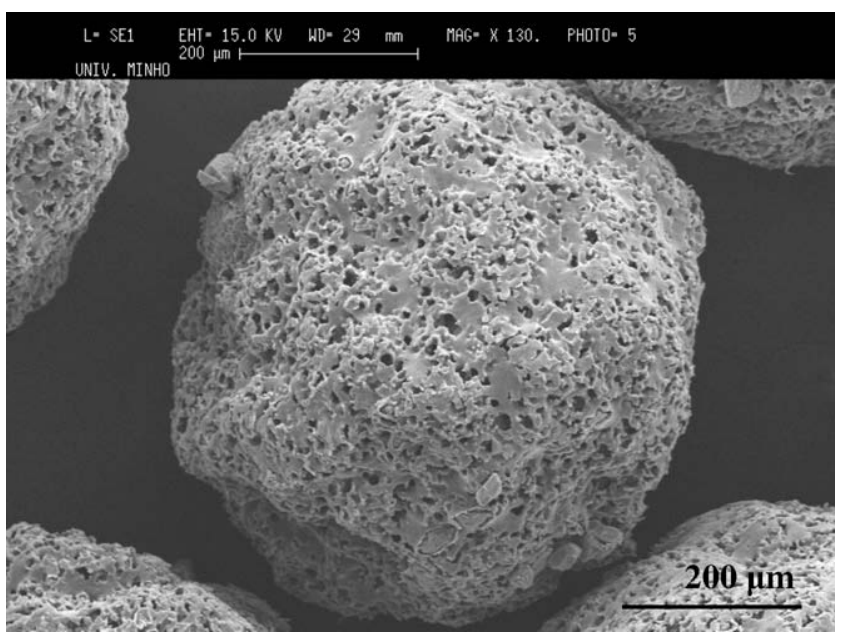

Fig. 6. SEM micrographs of SPCL-DEX-loaded microparticles (experimental condition IV: see Table 3).

Table 3

Effect of the initial amount of DEX on its encapsulation efficiency in the SPCL microparticles.

\begin{tabular}{lllll}
\hline Condition & $\%$ SPCL & $\begin{array}{l}\text { Particle size } \\
(\mu \mathrm{m})\end{array}$ & $\begin{array}{l}\text { Drug/polymer } \\
\text { ratio }(\mathrm{w} / \mathrm{w})\end{array}$ & $\begin{array}{l}\text { Loading } \\
\text { efficiency }(\%)\end{array}$ \\
\hline IV-DEX & 10 & $525.3 \pm 7.9$ & $1: 20$ & 74.99 \\
& & & $1: 10$ & 90.72 \\
& & $1: 5$ & 93.65 \\
\hline
\end{tabular}

similar to unloaded microparticles (see Figs. 1d and 6 for morphological comparison). A more compact surface was found and the particle size slightly increased as result of DEX entrapment. The quantification of the DEX, before and after loading, was performed by HPLC.

\subsubsection{Encapsulation efficiency}

For the determination of the encapsulation efficiency, the amount of DEX remaining in the reaction medium (unloaded DEX) was quantified. Table 3 shows the encapsulation efficiency values as a function of the initial amount of DEX added to the polymer solution. Higher values were obtained when $15 \%$ of DEX was added. There is a notable increase in the encapsulation efficiency when there is an increment from 5 to $10 \%$ in the initial DEX amount. However, increasing the initial amount of DEX higher than $10 \%$ yielded no significant increase in encapsulation efficiency. Taking these results into account, $15 \%$ was used as the initial amount of $\operatorname{DEX}(1: 5 \mathrm{drug} /$ polymer ratio) for the release studies.

\subsubsection{In vitro release of $D E X$ from SPLC microparticles}

Drug release from a polymeric matrix is controlled by a variety of factors, such as the solubility of the drug within the surrounding fluid, the size of the drug molecule and its mobility within the swollen polymeric network, and the dissolution rate of the polymer and polymer-drug interactions. Moreover, several authors have reported that the release kinetic is dependent on different characteristics of the microparticles (e.g. type of polymer, particle size and size distribution, surface morphology) [56-61], and these features can be controlled by the fabrication conditions. A number of studies in the literature have investigated the effect of fabrication conditions (e.g. interconnected pores and channels, emulsification medium concentration and polymer concentration) on the morphology of obtained microparticles, drug distribution and release kinetics $[56-58,60,61]$. Thus, understanding the influence of microparticle characteristics on the release behavior is important for yielding useful products that can meet different clinical applications.

The release profiles of DEX from SPCL microparticles during 30 days in PBS are illustrated in Fig. 7. The release in the first day is shown in more detail in the insert. The initial burst release is attributable to the release of the drug that is present at the outermost layer of the microparticles and is released quickly [4,27,62-63]. The burst release is then followed by a sustained release stage, which is most likely due to the hydrophobic character of poly(caprolactone) (PCL) polymer present in the microparticles and consequently its corresponding low permeability to water. The hydrophobicity of PCL $(70 \%$ in the blend) can cause a delay in water penetration and, consequently, the diffusion of the drug through the polymeric matrix into the aqueous release medium was retarded. On the other hand, it is necessary to take in consideration that the biodegradation of SPCL in PBS medium is slow [25] when compared with 


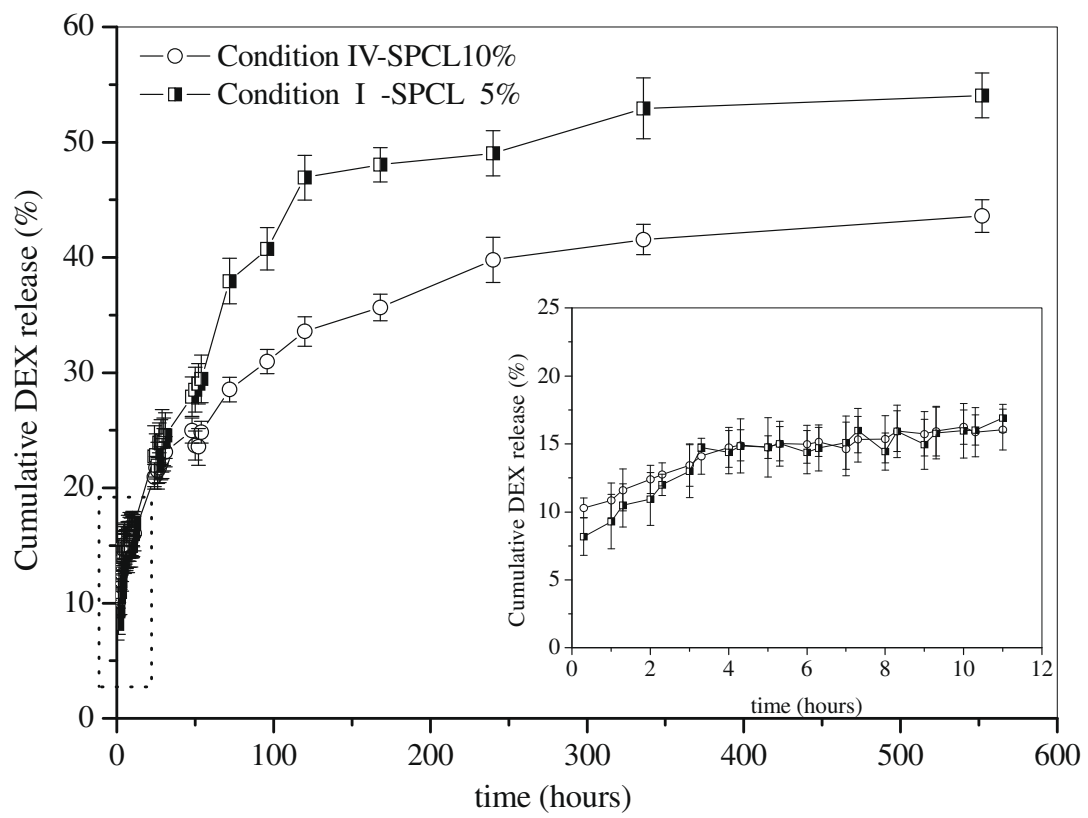

Fig. 7. In vitro release profiles of DEX from SPCL microparticles in PBS (pH 7.4, 0.1 M), at $37{ }^{\circ} \mathrm{C}$ and 50 rpm, for a period of 4 weeks. DEX-loaded SPCL microparticles obtained by the use of different polymer concentrations are compared. The insert graph shows the DEX release for a period of $11 \mathrm{~h}$.

other biodegradable polymers. Therefore, at the initial stages, the release of DEX from the SPCL microparticles is mainly controlled by diffusion mechanisms, and it is expected that the remaining drug in the polymeric matrix will be released as the degradation process becomes more significant.

When using higher polymer concentrations in the preparation of the microparticles (Fig. 7a and b) the drug release profile shows a more sustained pattern. This may be due to the fact that as the SPCL concentration increases, the particle size also increases, leading to a decrease in the total surface area of the microparticle system, reducing the area that is in direct contact with the water.

Further evidence of the loading and release of DEX from the SPCL microparticles was shown by FTIR analysis (Fig. 8). The FTIR spectrum of DEX-loaded SPCL micro-

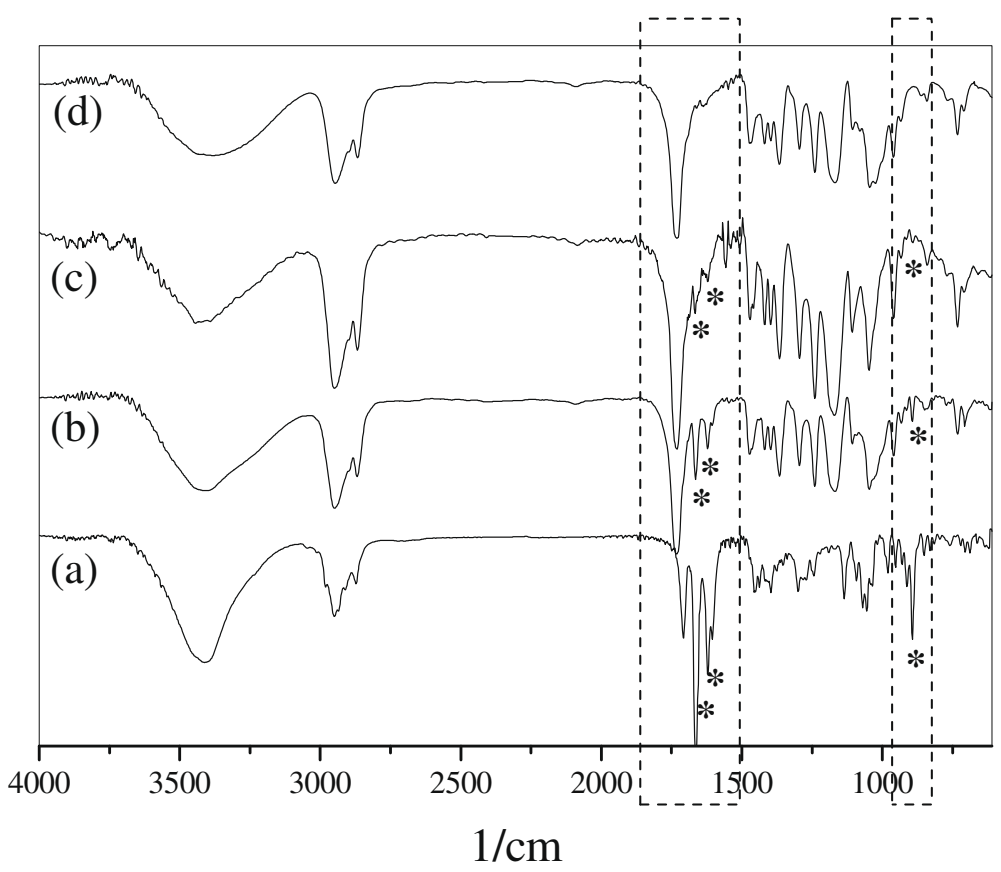

Fig. 8. FTIR spectra of DEX and SPCL microparticles: (a) DEX; (b) DEX-loaded microparticles; (c) DEX-loaded microparticles after 30 days of in vitro release; (d) unloaded SPCL microparticles. The characteristics bands of DEX are marked $(*)$. 


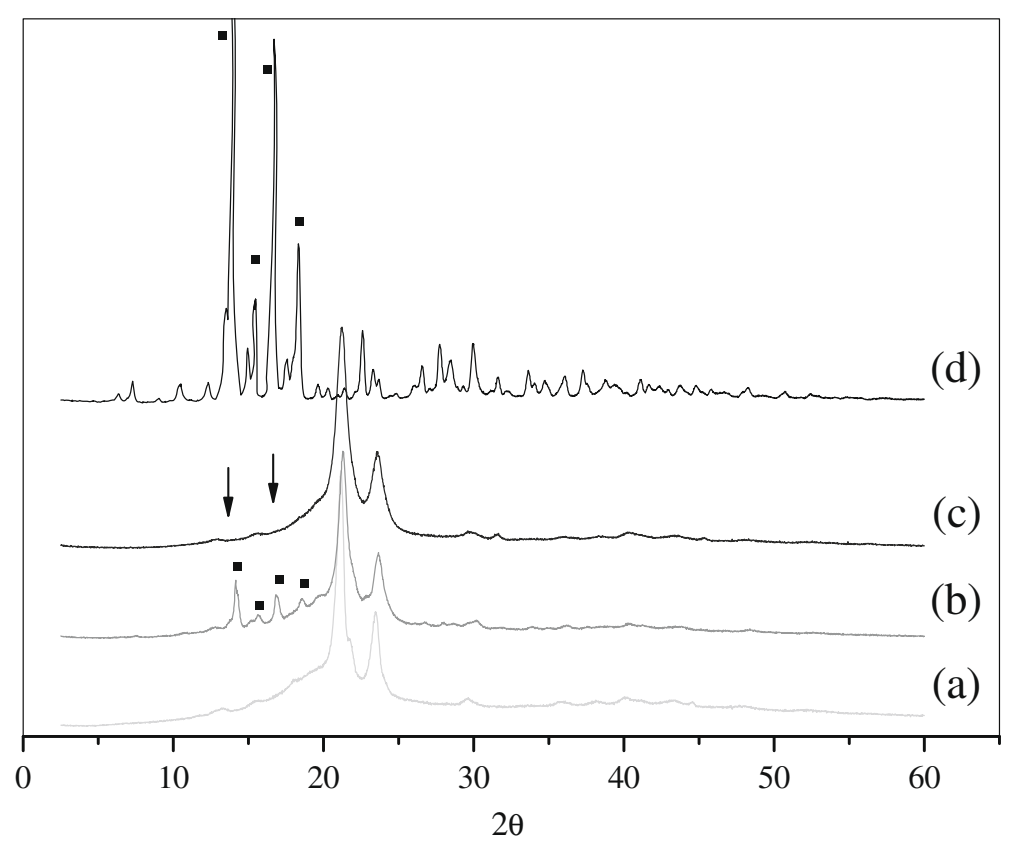

Fig. 9. XRD diffractograms of SPCL microparticles: (a) unloaded; (b) loaded with DEX; (c) DEX-loaded microparticles after 30 days of release; (d) DEX. The characteristics peaks of DEX are marked (ם).

particles (Fig. 8b) shows the characteristic bands of DEX, indicating the successful loading of the drug into the microparticles. After the release studies, it can be observed that there is a reduction in the intensity of the characteristic bands of DEX in the IR spectrum (Fig. 8c), due to the partial release of the drug from the microparticles. This result further indicates that the DEX present at the outermost layer of the microparticles is released quickly. The release profile obtained in this study, with an initial burst stage followed by a sustained release (typical of first-order release kinetic systems), is in accordance with the release behavior obtained with other delivery systems with similar composition [64].

The structure of the entrapped drug is also an important aspect to take into consideration in drug delivery systems, since it is known that transitions from amorphous to crystalline structures may occur. These transitions may affect the rate of drug release. For this purpose, XRD studies can show the physical nature of the encapsulated material. In Fig. 9 XRD diffractograms of DEX, unloaded SPCL microparticles and SPCL microparticles loaded with DEX after 30 days of in vitro release are presented. The XRD pattern of DEX shows several crystalline peaks, as marked in Fig. 9d. For the DEX-loaded SPCL microparticles it is possible to see the appearance of the characteristic peaks from the drug at low $2 \theta$, between $10^{\circ}$ and $20^{\circ}$, indicating the crystalline state of the DEX entrapped in the SPCL matrix. The maintenance of the crystalline structure may be due to the space available in the polymeric matrix (e.g. pore formation). Another confirmation of the in vitro DEX release can be observed in Fig. 9c, where the charac- teristics peaks of DEX are not observed after 30 days in PBS.

Several research groups are currently developing controlled release systems in the context of bone tissue engineering with the main goal of inducing in vitro the osteogenic differentiation of stem cells. A common problem associated with some of these systems is still in the lack of control over the drug release. Therefore, in this study we propose a very attractive drug delivery system, consisting of SPCL microparticles that can present diverse characteristics depending on the experimental conditions used during processing. The processing method can be adjusted to obtain particles with different sizes in the micron range, as well as with distinct surface morphologies from smooth to porous. Moreover, the developed SPCL microparticles were found to be biodegradable, noncytotoxic and biocompatible, as reported in a previous study [27]. The in vitro release studies of DEX, a widely used osteogenic agent, showed a sustained release pattern for a period of 30 days, indicating that the developed system might be very useful for the induction of osteoblastic differentiation of stem cells.

Further studies will be carried out in order to study the release behavior of DEX or other bioactive agents in the presence of enzymes in order to investigate the effect of matrix degradation on the release kinetics.

\section{Conclusions}

In this work the production of polymeric microparticles made from a blend of starch with polycaprolactone (SPCL) 
by means of an emulsion solvent evaporation technique was evaluated. Microparticles with different morphologies (smooth and porous) and sizes between 5 and $900 \mu \mathrm{m}$ could be obtained by using this methodology. Encapsulation of DEX into SPCL microparticles was performed with high encapsulation efficiencies, up to $93 \%$. The in vitro release studies showed a sustained release pattern for a period of 30 days, indicating the carrier potential of SPCL microparticles for the delivery of important bioactive agents. The developed systems might be very useful in the in vitro culturing of stem cells aimed at being committed into the osteoblastic lineage.

\section{Acknowledgments}

E.R.B. thanks the Marie Curie Host Fellowships for Early Stage Research Training (EST) "Alea Jacta EST" (MEST-CT-2004-008104) for providing her with a PhD Fellowship. This work was partially supported by the European NoE EXPERTISSUES (NMP3-CT-2004500283).

\section{References}

[1] Lakshmi SN, Laurencin CT. Biodegradable polymers as biomaterials. Prog Polym Sci 2007;32(8-9):762-98.

[2] Elvira C, Mano JF, San Román J, Reis RL. Starch-based biodegradable hydrogels with potential biomedical applications as drug delivery systems. Biomaterials 2002;23(9):1955-66.

[3] Coviello T, Matricardi P, Marianecci C, Alhaique F. Polysaccharide hydrogels for modified release formulations. J Control Release 2007;119(1):5-24.

[4] Malafaya PB, Silva GA, Reis RL. Natural-origin polymers as carriers and scaffolds for biomolecules and cell delivery in tissue engineering applications. Adv Drug Deliv Rev 2007;59(4-5):207-33.

[5] Lacerda De Paoli SH, Ingber B, Rosenzweig N. Structure-release rate correlation in collagen gels containing fluorescent drug analog. Biomaterials 2005;26(34):7164-72.

[6] George M, Abraham TE. Polyionic hydrocolloids for the intestinal delivery of protein drugs: alginate and chitosan - a review. J Control Release 2006;114(1):1-14.

[7] Price RD, Berry MG, Navsaria HA. Hyaluronic acid: the scientific and clinical evidence. J Plast Reconstr Aesthet Surg 2007;60:1110-9.

[8] Campoccia D, Doherty P, Radice M, Brun P, Abatangelo G, Williams DF. Semisynthetic resorbable materials from hyaluronan esterification. Biomaterials 1998;19(23):2101-27.

[9] MacIntosh AC, Kearns VR, Crawford A, Hatton PV. Skeletal tissue engineering using silk biomaterials. J Tissue Eng Regen Med 2008;2:71-80

[10] Altman GH, Diaz F, Jakuba C, Calabro T, Horan RL, Chen J, et al. Silk-based biomaterials. Biomaterials 2003;24:401-16.

[11] Ko JA, Park HJ, Hwang SJ, Park JB, Lee JS. Preparation and characterization of chitosan microparticles intended for controlled drug delivery. Int J Pharm 2002;249:165-74.

[12] Wang LY, Ma GH, Su ZG. Preparation of uniform sized chitosan microspheres by membrane emulsification technique and application as a carrier of protein drug. J Control Release 2005;106(1-2): $62-75$.

[13] Reis RL, Cunha AM. Starch Polymers. In: Buschow KHJ, Cahn RW, Flemings MC, Ilschner B, Kramer EJ, Mahajan S, Veyssie P, editors. Encyclopedia of materials: science and technology, vol. 11. New York: Elsevier Science; 2001. p. 8810-8816.
[14] Thomson RC, Wake MC, Yaszemski MJ, Mikos AG. Biodegradable polymer scaffolds to regenerate organs. Adv Polym Sci 1995; 122:245-74.

[15] Pereira CS, Cunha AM, Reis RL, Vazquez B, San Roman J. New starch-based thermoplastic hydrogels for use as bone cements or drug-delivery carriers. J Mater Sci Mater Med 1998;9(12):825-33.

[16] Mendes SC, Reis RL, Bovell YP, Cunha AM, van Blitterswijk CA, de Bruijn JD. Biocompatibility testing of novel starch-based materials with potential application in orthopaedic surgery: a preliminary study. Biomaterials 2001;22(14):2057-64.

[17] Malafaya PB, Elvira C, Gallardo A, San Roman J, Reis RL. Porous starch-based drug delivery system processed by a microwave route. J Biomater Sci Polym Ed 2001;12:1227.

[18] Boesel LF, Mano JF, Elvira C, San Roman J, Reis RL. In: Chiellini E, Solaro R, editors. Biodegradable polymers and plastics. New York: Kluwer Academic/Plenum Press; 2003. p. 243.

[19] Gomes ME, Sikavitsas VI, Behravesh E, Reis RL, Mikos AG. Effect of flow perfusion on the osteogenic differentiation of bone marrow stromal cells cultured on starch based three-dimensional scaffolds. J Biomed Mater Res A 2003;67:87-95.

[20] Gomes ME, Reis RL. Biodegradable polymers and composites in biomedical applications: from catgut to tissue engineering. Part I: Available systems and their properties. Int Mater Rev 2004;49(5):261-73.

[21] Malafaya PB, Stappers F, Reis RL. Starch-based microspheres produced by emulsion crosslinking with a potential media dependent responsive behavior to be used as drug delivery carriers. J Mater Sci Mater Med 2006;17(4):371-7.

[22] Marques AP, Reis RL, Hunt JA. The biocompatibility of novel starch-based polymers and composites: in vitro studies. Biomaterials 2002;23(6):1471-8.

[23] Gomes ME, Reis RL, Cunha AM, Blitterswijk CA, de Bruijn JD. Cytocompatibility and response of osteoblastic-like cells to starchbased polymers: effect of several additives and processing conditions. Biomaterials 2001;22(13):1911-7.

[24] Gomes ME, Godinho JS, Tchalamov D, Cunha AM, Reis RL. Alternative tissue engineering scaffolds based on starch: processing methodologies, morphology, degradation and mechanical properties. Mater Sci Eng C 2002;20(1-2):19-26.

[25] Azevedo HS, Gama FM, Reis RL. In vitro assessment of the enzymatic degradation of several starch based biomaterials. Biomacromolecules 2003;4(6):1703-12.

[26] Azevedo HS, Reis RL. In: Reis RL, San Roman J, editors. Biodegradable systems in tissue engineering and regenerative medicine. New York: CRC Press; 2005. p. 178.

[27] Balmayor ER, Tuzlakoglu K, Marques AP, Azevedo HS, Reis RL. A novel enzymatically-mediated drug delivery carrier for bone tissue engineering applications: combining biodegradable starch-based microparticles and differentiation agents. J Mater Sci Mater Med 2008; 19:1617-23.

[28] Taguchi T. Chemo-occlusion for the treatment of liver cancer: a new technique using degradable starch microspheres. Clin Pharmacokinet 1994;26(4):275-91.

[29] Bjork E, Edman P. Characterization of degradable starch microspheres as a nasal delivery system for drugs. Int J Pharm 1990;62(2):187-92.

[30] Fahlvik AK, Holtz E, Schroder U, Klaveness J. Magnetic starch microspheres, biodistribution and biotransformation. A new organspecific contrast agent for magnetic resonance imaging. Invest Radiol 1990;25(7):793-7.

[31] Silva GA, Costa FJ, Neves NM, Coutinho OP, Dias ACP, Reis RL. Entrapment ability and release profile of corticosteroids from starchbased microparticles. J Biomed Mater Res A 2005;73(2):234-43.

[32] Silva GA, Pedro A, Costa FJ, Neves NM, Coutinho OP, Reis RL. Soluble starch and composite starch Bioactive Glass 45S5 particles: synthesis, bioactivity, and interaction with rat bone marrow cells. Mater Sci Eng 2005;C 25:237-46. 
[33] Silva GA, Coutinho OP, Ducheyne P, Shapiro IM, Reis RL. Starchbased microparticles as vehicles for the delivery of active plateletderived growth factor. Tissue Eng 2007;13(6):1259-68.

[34] Touvinen L, Peltonen S. Drug release from starch-acetate microparticles and films with and without incorporated $\alpha$-amylase. Biomaterials 2004;25(18):4355-62.

[35] Wikingsson LD, Sjoholm I. Polyacryl starch microparticles as adjuvants in oral immunization, inducing mucosal and systemis immune responses in mice. Vaccine 2002;20(27-28):3355-63.

[36] Rydell N, Sjoholm I. Oral vaccination against diphtheria using polyacryl starch microparticles as adjuvant. Vaccine 2004;22(9):1265-74

[37] Nitsch MJ, Banakar UV. Implantable drug delivery. J Biomater Appl 1994;8(3):247-84.

[38] Langer R, Peppas NA. Advances in biomaterials, drug delivery, and bionanotechnology. AIChE J 2003;49(12):2990-3006.

[39] Meinel L, Illi OE, Zapf J, Malfanti M, Merkle HP, Gander B. Stabilizing insulin-like growth factor-I in poly(D,L-lactide-co-glycolide) microspheres. J Control Release 2001;70(1-2):193-202.

[40] Cleland JL, Duenas ET, Park A, Daugherty A, Kahn J, Kowalski J, et al. Development of poly-(D,L-lactide-co-glycolide) microsphere formulations containing recombinant human vascular endothelial growth factor to promote local angiogenesis. J Control Release 2001;72(1-3):13-24.

[41] Connolly AM, Schierbecker J, Renna R, Florence J. High dose weekly oral prednisone improves strength in boys with Duchenne muscular dystrophy. Neuromuscul Disord 2002;12(10):917-25.

[42] Kim HJ, Zhao H, Kitaura H, Bhattacharyya S, Brewer JA, Muglia $\mathrm{LJ}$, et al. Glucocorticoids suppress bone formation via the osteoclast. J Clin Invest 2006;116:2152-60.

[43] Galeska I, Kim TK, Patil SD, Bhardwaj U, Chattopadhyay D, Papadimitrakopoulos F, et al. Controlled release of dexamethasone from PLGA microspheres embedded within polyacid-containing PVA hydrogels. AAPS J 2005;7(1):22.

[44] Silva GA, Coutinho OP, Ducheyne P, Reis RL. Materials in particulate form for tissue engineering. 2. Applications in bone. J Tissue Eng Regen Med 2007;1(2):97-109.

[45] De Girolamo L, Sartori MF, Albisetti W, Brini AT. Osteogenic differentiation of human adipose-derived stem cells: comparison of two different inductive media. J Tissue Eng Regen Med 2007;1(2):154-7.

[46] Maxson S, Burg KJL. Conditioned media cause increases in select osteogenic and adipogenic differentiation markers in mesenchymal stem cell cultures. J Tissue Eng Regen Med 2008;2(2-3):147-54.

[47] Mano JF, Korianova D, Reis RL. Thermal properties of thermoplastic starch/synthetic polymer blends with potential biomedical applicability. J Mater Sci Mater Med 2003;14(2):127-35.

[48] Chasin M, Langer R, editorsBiodegradable polymers as drug delivery systems. New York: Marcel Dekker; 1990. p. 1-42.

[49] Rodriguez M, Vila-Jato JL, Torres D. Design of a new multiparticulate system for potential site-specific and controlled drug delivery to the colonic region. J Control Release 1998;55(1):67-77.
[50] Crotts G, Park TG. Preparation of porous and nonporous biodegradable polymeric hollow microspheres. J Control Release 1995;35(2-3):91-105.

[51] Benoit MA, Baras B, Gillard J. Preparation and characterization of protein-loaded poly( $\varepsilon$-caprolactone) microparticles for oral vaccine delivery. Int J Pharm 1999;184(1):73-84.

[52] Avérous L. Biodegradable multiphase systems based on plasticized starch: a review. J Macromol Sci C - Polym Rev 2004;44(3):231-74.

[53] Elzein T, Nasser-Eddine M, Delaite C, Bistac S, Dumas P. FTIR study of polycaprolactone chain organization at interfaces. J Colloids Interfaces Sci 2004;273(2):381-7.

[54] Pashkuleva I, Marques AP, Vaz F, Reis RL. Surface modification of starch based blends using potassium permanganate-nitric acid system and its effect on the adhesion and proliferation of osteoblast-like cells. J Mater Sci Mater Med 2005;16(1):81-92.

[55] Barikani M, Mohammadi M. Synthesis and characterization of starch-modified polyurethane. Carbohydr Polym 2007;68:773-80.

[56] Igartua M, Hernandez RM, Esquisable A, Gascon AR, Calvo MB, Pedraz JL. Influence of formulation variables on the in vitro release of albumin from biodegradable microparticulate systems. J Microencapsul Micro Nano Carriers 1997;14(3):349-56.

[57] O'Hagan DT, Jeffery H, Davis SS. The preparation and characterization of poly(lactide-co-glycolide) microcapsules: III. Microparticle/ polymer degradation rates and the in vitro release of a model protein. Int J Pharm 1994;103(1):37-45.

[58] Sah HK, Toddywala R, Chien YW. The influence of biodegradable microcapsule formulations on the controlled release of a protein. $\mathrm{J}$ Control Release 1994;30(3):201-11.

[59] Giunchedi P, Conti B, Maggi L, Conte U. Cellulose acetate butyrate and polycaprolactone for ketoprofen spray-dried microsphere preparation. J Microencapsul Micro Nano Carriers 1994;11(4):381-93.

[60] Embleton JK, Tighe BJ. Polymers for biodegradable medical devices. X. Microencapsulation studies: control of poly-hydroxybutyrate-hydroxyvalerate microcapsules porosity via polycaprolactone blending. J Microencapsul Micro Nano Carriers 1993;10(3):341-52.

[61] Yang Y-Y, Chung T-S, Ng NP. Morphology, drug distribution, and in vitro release profiles of biodegradable polymeric microspheres containing protein fabricated by double-emulsion solvent extraction/ evaporation method. Biomaterials 2001;22(3):231-41.

[62] Jameela SR, Suma N, Jayakrishnan A. Protein release from poly( $\varepsilon-$ caprolactone) microspheres prepared by melt encapsulation and solvent evaporation techniques: a comparative study. J Biomater Sci Polym Ed 1997;8(6):457-66.

[63] Silva GA, Ducheyne P, Reis RL. Materials in particulate form for tissue engineering. 1. Basic concepts. J Tissue Eng Regen Med 2007;1(1):4-24.

[64] Yoon JJ, Kim JH, Park TG. Dexamethasone-releasing biodegradable polymer scaffolds fabricated by a gas-foaming/salt-leaching method. Biomaterials 2003;24(13):2323-9. 